Secher, Matthieu; André, Aurélie; Valette, Eric; Besnier, Anne-Laure; Tassi, Pablo Numerical modelling of the sediment dynamics in Saint-Martin-la-Porte reservoir, France

Zur Verfügung gestellt in Kooperation mit / Provided in Cooperation with: TELEMAC-MASCARET Core Group

Verfügbar unter / Available at:

https://hdl.handle.net/20.500.11970/104498

Vorgeschlagene Zitierweise / Suggested citation:

Secher, Matthieu; André, Aurélie; Valette, Eric; Besnier, Anne-Laure; Tassi, Pablo (2017): Numerical modelling of the sediment dynamics in Saint-Martin-la-Porte reservoir, France. In: Dorfmann, Clemens; Zenz, Gerald (Hg.): Proceedings of the XXIVth TELEMAC-MASCARET User Conference, 17 to 20 October 2017, Graz University of Technology, Austria. Graz: Graz University of Technology. S. 139-145. 


\title{
Numerical modelling of the sediment dynamics in Saint-Martin-la-Porte reservoir, France
}

\author{
Matthieu Secher ${ }^{1}$, Aurélie André ${ }^{1}$, Eric Valette ${ }^{1}$, Anne- \\ Laure Besnier ${ }^{2}$, Pablo Tassi ${ }^{2,3}$ \\ ${ }^{1} \mathrm{EDF} \mathrm{CIH}$ \\ ${ }^{2}$ EDF R\&D \\ ${ }^{3}$ Saint-Venant Hydraulics Laboratory \\ matthieu.secher@edf.fr
}

Abstract - The Saint-Martin-La-Porte reservoir is located on the River Arc in the French Alps. Launched recently, an operational plan seeks to optimize its sediment management and to study the opportunity of restoring its storage capacity.

This work presents two models: the first model is built in order to reproduce the evolutions induced by annually flushing operation; the second model is built to simulate deposition in the reservoir during an 8 months period while the reservoir is operated normally. Results of these two models are both compared with measurements, bathymetries realized before and after a flushing operation for the first one, and measurements of sediment concentrations for the second one.

Best results for the flushing model were obtained using bedload transport model with a non-uniform sediment grain size distribution, whereas the deposition processes were simulated using suspended load transport model. The results of the two models are in good agreement with the measurements. In the case of the flushing model, numerical results indicated a very realistic mixing of the different sediment grain sizes modelled. For the deposition model, flow recirculation zones are well reproduced and led to deposition zones identified on the bathymetries.

\section{INTRODUCTION}

The Saint-Martin-La-Porte (SMLP) reservoir is located on the River Arc in the northern French Alps. This river is a main tributary of the Isère River, which is a tributary of the Rhône River (see Fig. 1).

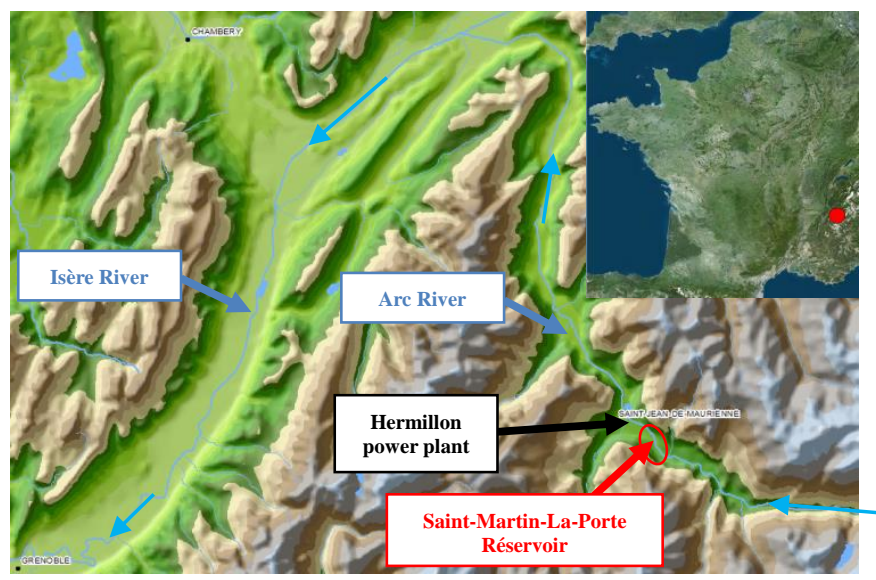

Figure 1. The Saint-Martin-La-Porte reservoir location in Arc River valley (northern French Alps).

The SMLP dam, built in 1986, has a storage capacity around $100,000 \mathrm{~m}^{3}$ and receives drainage from an area of $1,167 \mathrm{~km}^{2}$. It consists of three wide river gates with a water intake located on the right side of the dam (see Fig. 2). It allows diverting $90 \mathrm{~m}^{3} / \mathrm{s}$ to the Hermillon hydro-power plant.

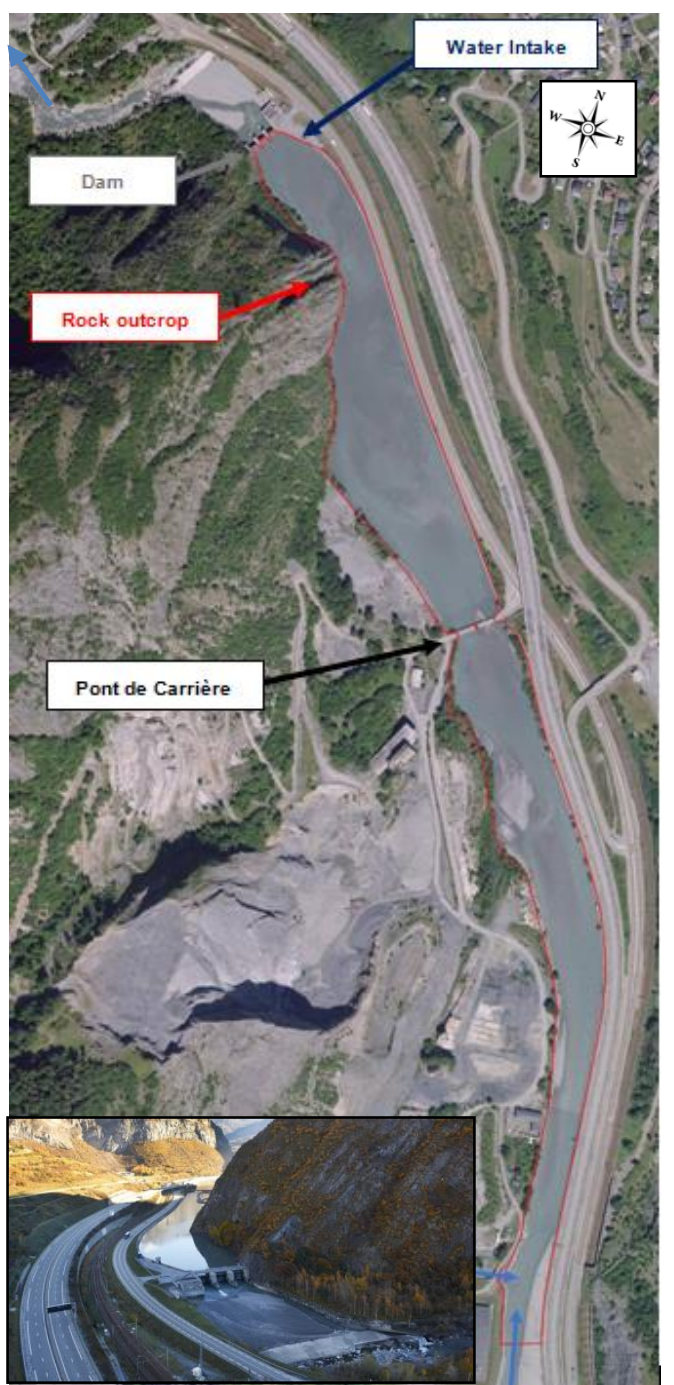

Figure 2. Orthophotography of the reservoir (with the area of the model in red) and picture of the dam from downstream point of view. 
Suspension sediment transport is important on the Arc River with around 100,000 tons per year. There is also bedload sediment transport on this river, since the grain size distribution is large (from silt to gravel, including sand). There is also bedload sediment transport on this river but it is complicated to estimate an order of magnitude (probably less than suspension sediment transport).

The SMLP dam is trapping a significant part of this sediment transport. To manage these deposits, once a year the dams of the Arc River are flushed for around 12 hours in order to evacuate as much sediments as possible. These annually operations are done in June, unless a strong enough flood of the Arc River to clear reservoirs happen before the planned date.

In order to better understand sedimentation processes in the SMLP reservoir, two Telemac-2D-Sisyphe models have been implemented:

- $\quad$ one to model a flushing event ;

- one to model an 8 months period while the reservoir is operated normally.

The aim of this work is to provide a better understanding of the sediments processes in order to optimize the management of sediments in this reservoir and to study the opportunity to restore its storage capacity.

\section{MODELLING OF FLUSHING EVENT}

\section{A. Input data}

A hydraulic model (Telemac-2D) has been built using a bathymetry survey done in 2015. This model has been calibrated (friction coefficient mainly) using current surveys (LSPIV ${ }^{1}$ and velocity profiles). The hydrodynamic model is used as a basis for the development of the sediment transport model using Sisyphe.

The flushing event of June 2012 is used to calibrate the model as this event is well monitored:

- measurements of the inflow discharge and water elevation in the reservoir during the event (see Fig. 3);

- bathymetries before and after the event (see Fig. 4);

- measurements of the suspension sediment concentration upstream and downstream the dam.

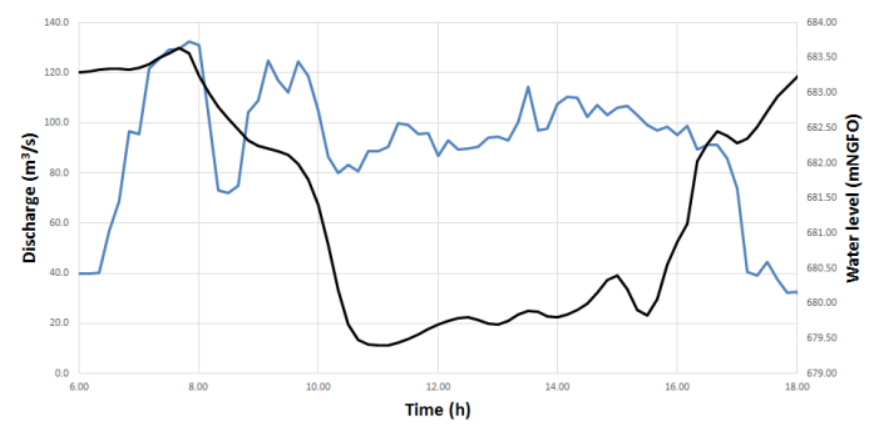

Figure 3. Upstream hydrograph and water level at the dam during the flushing of $2012^{2}$

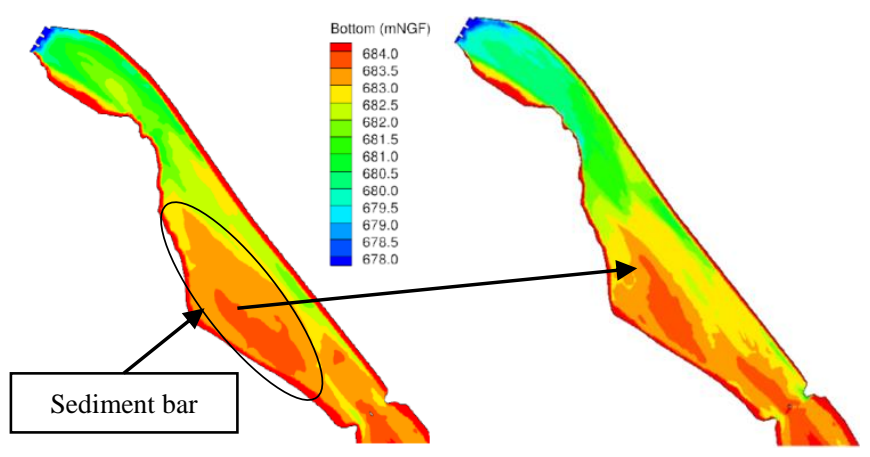

Figure 4. Bathymetry before the 2012 flushing event (left); bathymetry after the flushing of 2012 (right)

A grain size survey in the reservoir was also completed in 2012. It shows the grain size sorting along the reservoir with coarse sediment upstream $(13 \mathrm{~mm})$ and fine sediment downstream $(<300 \mu \mathrm{m})$, with sands in-between (from 0.3 to $2 \mathrm{~mm})$.

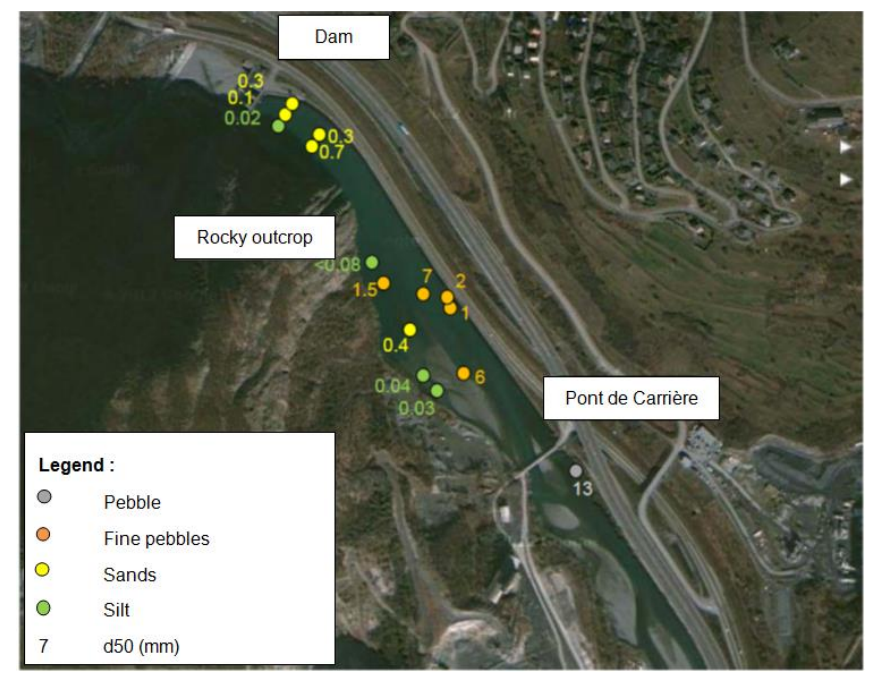

Figure 5. Map of the grain size survey of 2012.

${ }^{2}$ NGFO : stands for "Nivellement Général Orthométrique de France" (Orthometric height system of France)

\footnotetext{
${ }^{1}$ LSPIV : Large-Scale Particle Image Velocimetry
} 


\section{B. Model}

The hydraulic model is a Telemac-2D [1] [2] [3] model using the V7P0 version. For sedimentology part, Sisyphe module [4] of the same version is used.

\section{Mesh}

The model area (see Fig. 2) is approximately $1.5 \mathrm{~km}$ long and in average $80 \mathrm{~m}$ wide. The convergence of the model and the mesh dependence were studied by analyzing the velocity distribution at selected profiles. Sensitivity tests for mesh resolution showed that a discretization of 114,000 elements (58,000 nodes), with medium mesh size ranging from $2 \mathrm{~m}$ (downstream) to $3 \mathrm{~m}$ (upstream) is a good compromise between model efficiency and simulation time.

\section{Boundary conditions}

The boundary conditions are indicated on Fig. 6 and the different characteristics and values used through this study are summarized in the table below.

TABLE 1. BOUNDARY CONDITIONS

\begin{tabular}{|c|c|c|}
\hline \multirow{2}{*}{$\mathbf{N}^{\circ}$} & \multicolumn{2}{|c|}{ Boundary conditions } \\
\cline { 2 - 3 } $\begin{array}{c}1 \\
\text { (Arc River) }\end{array}$ & Prescribed variable & Values \\
\hline $\begin{array}{c}\text { Inflow discharge } \\
\text { (water } \\
\text { intake) }\end{array}$ & Water level & {$[682.5-684] \mathrm{mNGFO}$} \\
\hline $\begin{array}{c}3 \\
\text { (river gate) }\end{array}$ & Outflow discharge & $\sim 0 \mathrm{~m}^{3} / \mathrm{s}$ \\
\hline $\begin{array}{c}4 \\
\text { (outflow) }\end{array}$ & Outflow discharge \\
\hline $\begin{array}{c}5 \\
\text { (river gate) }\end{array}$ & Outflow discharge & $1.1 \mathrm{~m}^{3} / \mathrm{s}$ \\
\hline $\begin{array}{c}6 \\
\text { (river gate) }\end{array}$ & Outflow discharge & $\sim 0 \mathrm{~m}^{3} / \mathrm{s}$ \\
\hline $\begin{array}{c}7 \\
\text { (tributary) }\end{array}$ & Inflow discharge & $\sim 0 \mathrm{~m}^{3} / \mathrm{s}$ \\
\hline
\end{tabular}
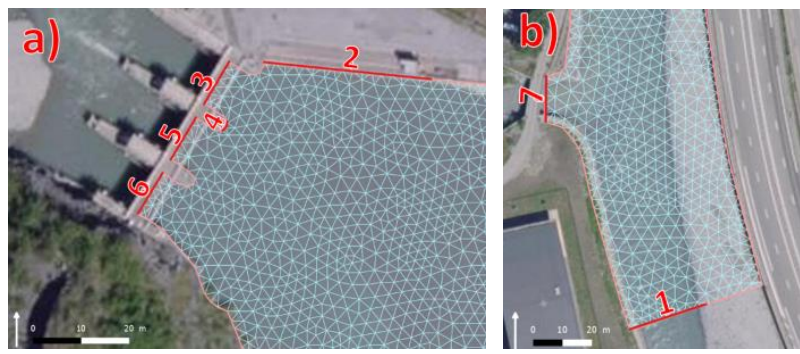

Figure 6. Downstrem boundary conditions (left), upstrem boundary condition (right).

To model normal management conditions, the three river gates are closed and all the flow is diverted through the water intake. These boundary conditions are described in Tab. 1.

During the flushing event, all the flow passes through the river gates which are opened alternatively (see Fig. 7). To represent this sequence in the model, the Telemac-2D subroutine bord. $f$ has been modified to change the type of river gates boundary condition $\left(\mathrm{N}^{\circ} 3,5\right.$ and 6$)$ during simulation. When the gates are opened, the prescribed state on their boundaries is water level prescribed. The boundary condition for the water intake is also changed from water level prescribed to outflow discharge prescribed equal to $0 \mathrm{~m}^{3} / \mathrm{s}$ (there is no hydroelectric production during a flushing event).

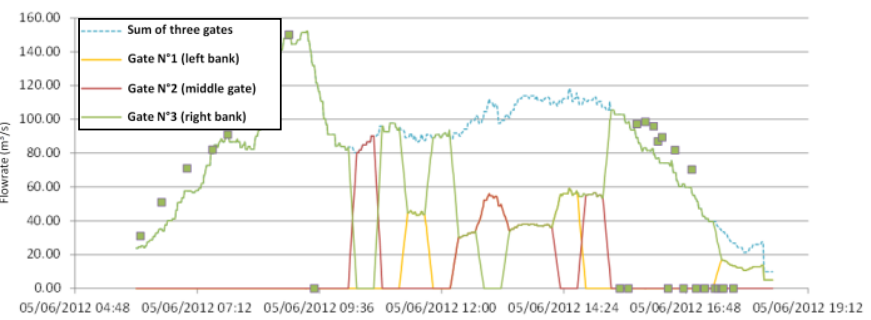

Figure 7. Opening gates sequence during the 2012 flushing of SMLP reservoir (green squares are theortical discharge of the dam calculated with the water level measured).

\section{Sediment model}

It was initially assumed that the sediments eroded in the reservoir were mainly transported by suspension. Preliminary results with this transport model were very far from reality. A bedload sediment transport model turned out to be much better (suspended + bedload model were not tested here).

The first lesson from this model is that bedload transport during flushing event in SMLP reservoir is significant and more importantly, that the reservoir morphology is mainly modified by bedload sediment transported.

For the bedload sediment transport model, sediment boundaries conditions are set on equilibrium sediment discharge on boundaries $n^{\circ} 1$ and $7($ LIEBOR $=5)$ and on free sediment outflow discharge $(\mathrm{LIEBOR}=4)$.

The bedload transport formula which provides the best results in this case is the Engelund-Hansen formula (bedload formula 30 in Sisyphe). This transport formula, appropriate for non-uniform sediment distribution, was calibrated on a total transport physical model, with bedload and suspension transport on sand [4].

The Meyer-Peter and Mueller formula initially tested yielded inferior results, especially downstream in the fine sediment areas.

The sediment slide module was used with an equilibrium angle of 30 degrees and others slope effects were activated with the default values (correction of direction of bedload transport and intensity of bedload transport rate, but no secondary currents effect). Finally, in this case, the best results were obtained with no skin friction correction $(\mu=1)$.

To get a realistic sediment model of this reservoir with highly variable grain sizes, four zones have been defined 
with four representative mean diameter classes by simplifying and interpolating the grain size survey of 2012 . These zones are applied in the code with the inpoly function in init_compo.f Sisyphe subroutine. Several grain sizes were tested in the different areas to try to calibrate the model to obtain a bottom elevation as close as possible to measurements. The best results were obtained with the configuration shown in Fig. 8.

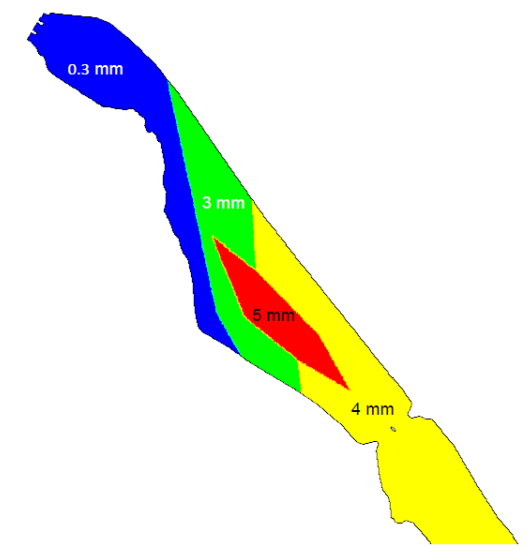

Figure 8. Map of the grain size allocation defined in the model drawn from simplification of 2012 grain size survey

The moveable bed has been defined $3 \mathrm{~m}$ thick below the initial bathymetry, constant in the entire model but only in zones where the bottom is constituted of sediment. It is done by the modification of noerod.f Sisyphe subroutine.

Finally, main fixed parameters of the simulations are resumed in the Tab. 2.

TABLE 2. MAIN MODEL PARAMAETERS

\begin{tabular}{|c|c|}
\hline Parameters & Values \\
\hline Time step & $0.1 \mathrm{~s}$ \\
\hline Simulation duration & $45000 \mathrm{~s}$ \\
\hline $\begin{array}{c}\text { Strickler coefficient } \\
\text { Hydraulic numerical } \\
\text { scheme }\end{array}$ & Characteristics method \\
\hline $\begin{array}{c}\text { Sediment numerical } \\
\text { scheme }\end{array}$ & Edged-based N-scheme \\
\hline $\begin{array}{c}\text { Sediment transport } \\
\text { formula }\end{array}$ & Engelund-Hansen \\
\hline $\begin{array}{c}\text { Sediment slide } \\
\text { (slope stability of } 30^{\circ} \text { ) }\end{array}$ \\
\hline $\begin{array}{c}\text { Secundary currents } \\
\text { No }\end{array}$ \\
\hline $\begin{array}{c}\text { Slope effects } \\
\text { No }\end{array}$ \\
\hline
\end{tabular}

\section{Results}

The best results obtained with this model are shown in Fig. 9 and for two cross sections in Fig. 10. The comparison between the bathymetry after the flushing event of 2012 and the numerical results shows that the simulated final bottom level is close to the measurements, especially downstream the reservoir (see cross section $\mathrm{C} 1$ in Fig. 10).

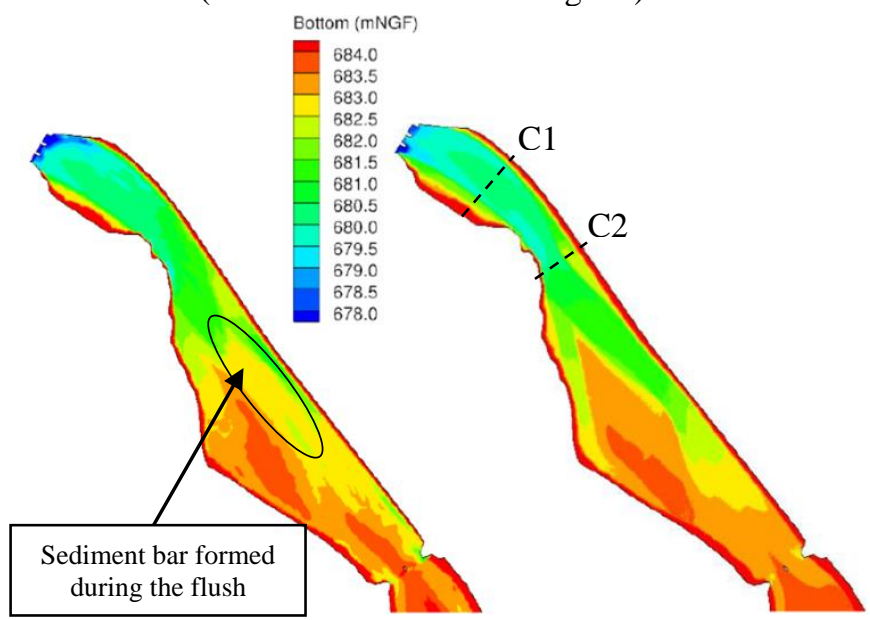

Figure 9. Measured bathymetry after the flushing of 2012 (left); final numerical results of the Telemac-2D-Sisyphe model (right).
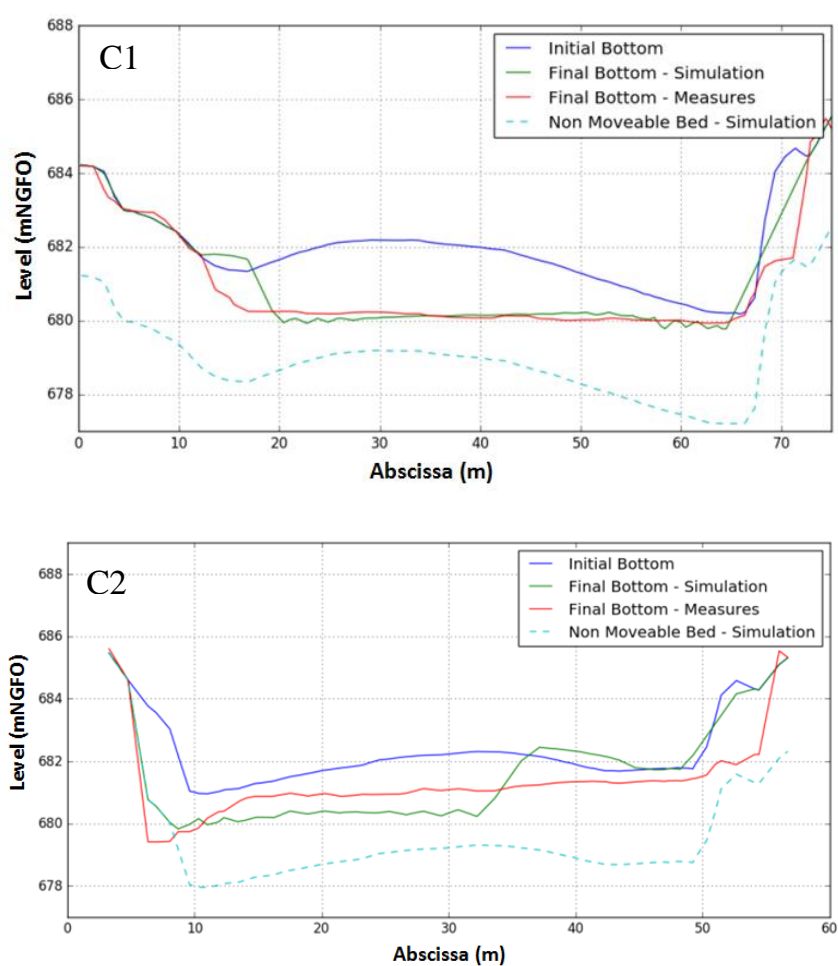

Figure 10. Initial bottom, non-moveable bed of the model and simulated and measured final bottom after the flushing event for cross-section C1 around $100 \mathrm{~m}$ upstream the dam (top) and cross-section C2 around $250 \mathrm{~m}$ upstream the dam (bottom).

$400 \mathrm{~m}$ upstream of the dam, the agreement between the results and the measurements is not as good. First, in the main channel, a sediment bar formed during the flush (see 
Fig. 9) is not captured by the model. Otherwise, the top of the bar present before the flush on the left of the reservoir is moving from the left to the right of the bar during the flush (see Fig. 4). This reconfiguration is not captured either.

Several hypotheses can explain these differences:

- There are not enough grain sizes zones and their initial distribution is not precise enough;

- the definition of only one grain size per zone is highly unlikely and cannot capture complex evolution;

- no suspension sediment transport is modelled, especially for upstream suspension influx which can deposit during and after the flush;

- the final bathymetry was realised several days after the flush. Some reconfigurations and deposits may have happened between the end of the flush and the measurements.

However, the simulated sediment volume balance between before and after the flush is very close to the measurement:

- $\quad$ Simulated: $-18,800 \mathrm{~m}^{3}$;

- $\quad$ Measured: $-19,500 \mathrm{~m}^{3}$.

Another interesting result is the mean diameter distribution at the end of the simulation (see Fig. 11). These results show that coarse sediment can progress in the reservoir and can exit the reservoir with several flushes. It also shows that there is a mix of grain size sediment during the flush and consequently, validates the hypothesis that the initial grain size allocation is too simple.

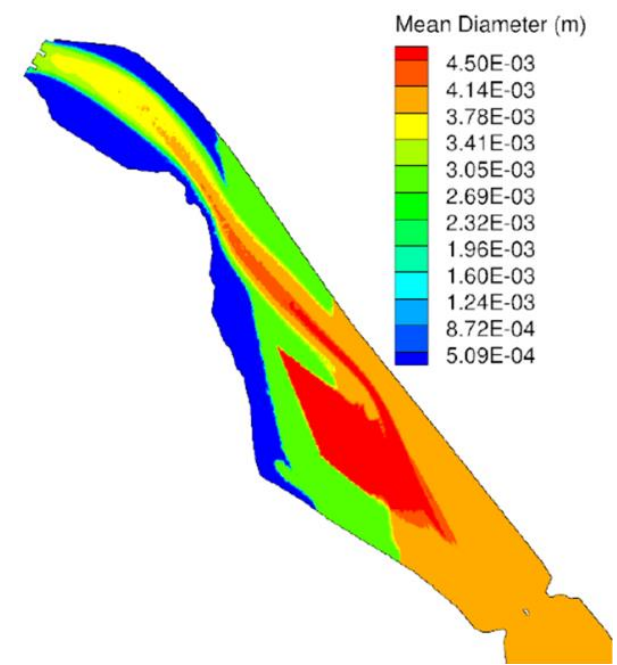

Figure 11. Map of the grain size allocation at the end of the simulation

\section{Comparison with $1 D$ results}

A 1D-model of SMLP has also been constructed at CIH with Cavalcade, a software developed by Artelia. Cavalcade is a 1D hydraulic and sediment transport model. The geometry is constituted of cross-section profiles simplified with one bottom level value for each cross-section calculated from the average of the river bed for the initial geometry. The same cross-section average has been done on the Telemac 2D-Sisyphe results. The comparison between Cavalcade model calibrated on the 2012 flush and the Telemac 2D-Sisyphe is shown in Fig. 12 on a longitudinal profile. The Cavalcade results were obtained with EngelundHansen formula and a mean grain size of $4.4 \mathrm{~mm}$ (no multi grain approach).

The results are very close and it shows that, even if the Telemac-2D-Sisyphe model is not in perfect accordance with the measurements on transversal sediment evolution, it is in very good agreement and as good as Cavalcade 1Dmodel for the longitudinal bottom level evolution.

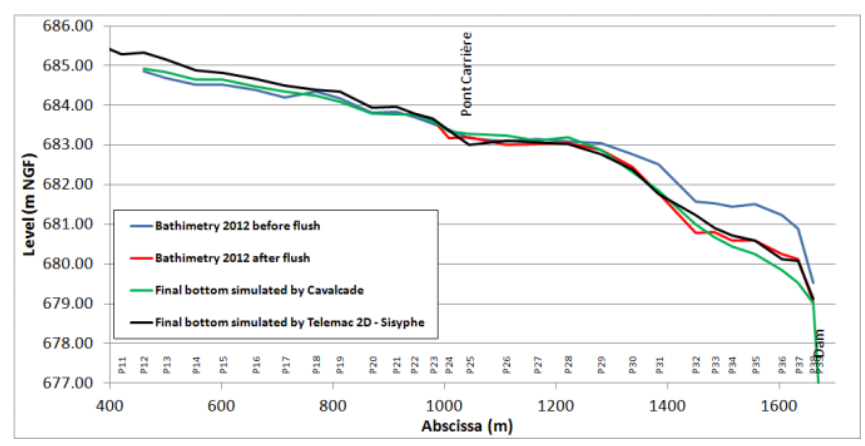

Figure 12. Longitudinal profile of bathymetries of SMLP before and after the flush of 2012, and Cavalcade and Telemac 2D-Sisyphe simulated final bottom.

\section{MODELLING OF STANDARD MANAGEMENT OF THE RESERVOIR}

Another model of SMLP reservoir was built, with the aim to model the sediment dynamic during standard management of the reservoir (without flush). One of the objectives was to specify the sedimentation rate inside the reservoir, which is estimated to be lower than $5 \%$ of the sediment influx according to experts.

\section{A. Input data}

The same hydraulic model is used for this model. Only the geometry is modified and, no treatment of boundary conditions like in the flushing model is performed, since gates are kept closed during the simulation.

The measured bathymetry from 2013 of the reservoir is used. This bathymetry was chosen because it is the only one with a long period before the next flush ( 8 months) and with relatively complete upstream measurements of sediment influxes (turbidity prone), inflow discharge and reservoir water level.

\section{B. Model}

For this model, the sediment transport is modelled using the Sisyphe suspension sediment transport model. In standard management of the reservoir without drawdown of the reservoir level, the shear stress is not sufficient to significantly move gravels or sands. 
Hence, this model is mainly a sediment deposition model. Thus, the bottom of the model is defined as nonmoveable with the noerod.f subroutine.

During standard management period of the reservoir a non-cohesive behaviour of the sediments in suspension is assumed. Hence, the Partheniades formula is used for erosion and the Krone formula is used for deposition. The settling velocity of the sediments is set according to measurements of the Arc sediments [5].

The main issue with this model was the accuracy of discharge and water level boundary conditions. For many periods during the simulation period of 8 months the upstream measured discharge was not high enough to actually sustain the measured water level rising in the reservoir. Due to these input data problems, simulation crashed. The modelling of the bed evolutions even increased this issue.

The principal reason was a problem of synchronism between the different measured upstream discharges combined to get the main discharge imposed at the upstream boundary condition. Errors in these different measured discharges or in bathymetric data are also an explanation. Finally, some small tributaries are not taking into account because their discharges are not measured and they can contribute to this disequilibrium.

The only solution found to solve this problem was to increase manually the upstream inflow discharge when it was not sufficient.

The eight month simulation was performed on EDF R\&D cluster named Porthos. On 56 cores, the run lasted about 40 hours.

\section{Results}

Fig. 13 shows the final simulated bed evolution. This calculation highlights 3 major zones of sedimentation. Two of these zones are due to hydraulic recirculation zones. The third one corresponds to slow currents just upstream the sluice gates of the dam.

These deposits zones were obvious from bathymetries analysis and the model was able to correctly capture them.

The calculated deposits along the limit between dried and wet mesh (relatively large because of the water level fluctuations) is less obvious on the bathymetry analysis.

The simulated sedimentation rate during these eight months is $4.6 \%$ of influx sediment; this rate confirms the expert estimation.

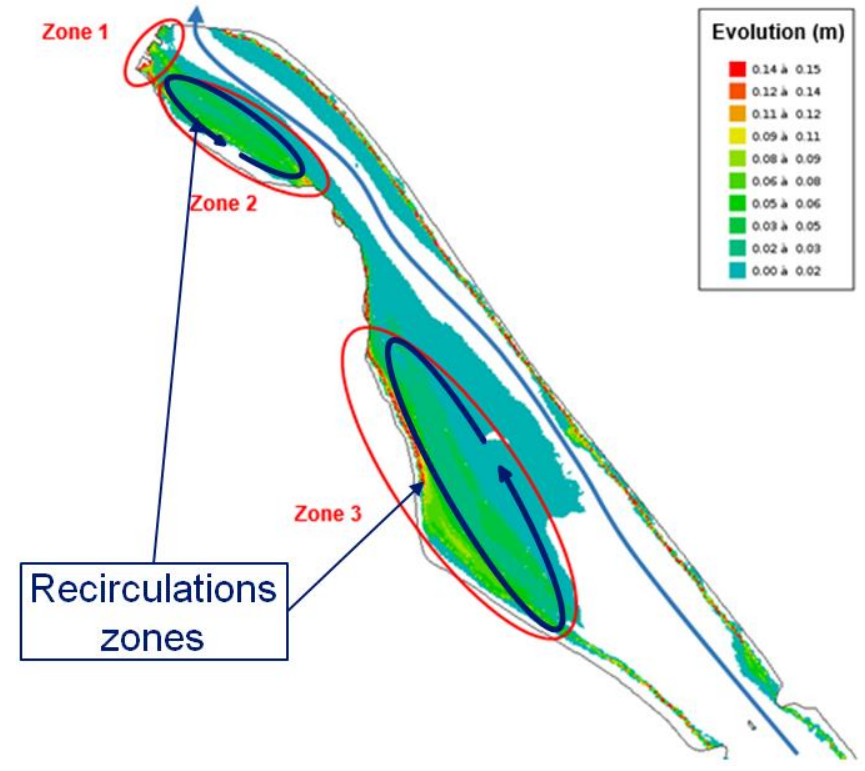

Figure 13. Final bed evolution (initial bottom level minus final bottom level) of 8 month simulation.

\section{CONCLUSION AND PERSPECTIVES}

Two Telemac-2D-Sisyphe models have been developed, one to simulate sediment dynamics during a flushing event and the other one, to model sediment dynamics during a period of standard management of the reservoir.

The model of the flushing event yields to results in good agreement with the bathymetric measurements. It proves that bedload sediment transport mode is the dominant process during a flush of the SMLP reservoir. This model allows simulating the mixing of different sediment grain sizes in the reservoir and indicates that gravel can pass through the dam with several flushes.

However, the model shows that the initial description of the grain size distribution must be very precise to get good results in the transversal directions.

Results obtained with the second model, developed to study deposition in a standard period of time with no flush, are $a$ priori good. It strengthens the expert evaluation on the sedimentation rate and it helps to understand sediment dynamics in the reservoir. It allows anticipating sedimentations problem in the reservoir like for example deposits in front of gates which can compromise there opening.

These models can now be used to optimize sediment management of the SMLP reservoir (dredge plan, opening sequence of gates during flush, etc.).

\section{ACKNOWLEDGEMENT}

The authors thank Artelia for their permission to use Cavalcade results in this article. 


\section{REFERENCES}

[1] Hervouet J.-M. (2007) Hydrodynamics of Free Surface Flows. Modelling with the finite element method. John Wiley \& Sons, Ltd.

[2] Open-Telemac webpage (2017) www.opentelemac.org

[3] Ata R. V7P0 Telemac 2D User Manual

[4] Tassi P. V7P0 Sisyphe User Manual

[5] Antoine G. (2013) Dynamique des matériaux en suspension (MES) le long des rivières aménagées ; exemple de l'Arc en Maurienne et de l'Isère, $\mathrm{PhD}$ Thesis, Université de Grenoble 